\title{
EARTH'S CARBON CYCLE: A MATHEMATICAL PERSPECTIVE
}

\author{
DANIEL H. ROTHMAN
}

\begin{abstract}
The carbon cycle represents metabolism at a global scale. When viewed through a mathematical lens, observational data suggest that the cycle exhibits an underlying mathematical structure. This review focuses on two types of emerging results: evidence of global dynamical coupling between life and the environment, and an understanding of the ways in which smaller-scale processes determine the strength of that coupling. Such insights are relevant not only to predicting future climate but also to understanding the long-term co-evolution of life and the environment.
\end{abstract}

\section{INTRODUCTION}

The concentration of carbon dioxide in the atmosphere is rising (Figure 10) as a consequence of the burning of fossil fuels 39,72 . Because $\mathrm{CO}_{2}$ traps heat, Earth's climate is expected to become warmer [5, 57. These observations alone make the fluxes of carbon into and out of the atmosphere a matter of intense current interest 71 . But there is a bigger story here, one that has played out since the origin of life.

Plants, fueled by the Sun's radiation, convert $\mathrm{CO}_{2}$ to sugar and other carbohydrates by photosynthesis. Organisms that consume plants derive their energy from the oxidation of those photosynthetic products. Further up the food chain, organisms that consume other consumers ultimately derive their energy from the same source. In these ways, the $\mathrm{CO}_{2}$ that had been taken out of the atmosphere and oceans by plants is returned from where it came; the process is called respiration. Integrated over all organisms and all environments, the loop between photosynthesis and respiration makes up the biological component of Earth's carbon cycle. The flux through the loop is enormous: about one hundred gigatons ( 1 gigaton $=10^{15}$ grams) of carbon pass through it each year [37, more than an order of magnitude greater than the present rate of fossil fuel emissions [12].

The loop, however, contains a tiny leak [10,36. About $0.1 \%$ of the organic carbon produced by photosynthesis escapes respiration and instead becomes rock. Geologic processes normally bring the rock back to the surface environment, where the ancient organic matter is oxidized; the previously buried carbon then finally reenters the atmosphere as $\mathrm{CO}_{2}$. The extraction and burning of fossil fuels amounts to a roughly hundred-fold speed up of the leak's natural rate of reinjection.

Received by the editors May 30, 2014.

2010 Mathematics Subject Classification. Primary 86-02; Secondary 92B99.

I would like to thank T. Bosak, C. Follett, and D. Forney for collaborations on problems discussed in Section 2 This work was supported by NASA Astrobiology (NNA08CN84A and NNA13AA90A) and NSF (OCE-0930866 and EAR-1338810). 


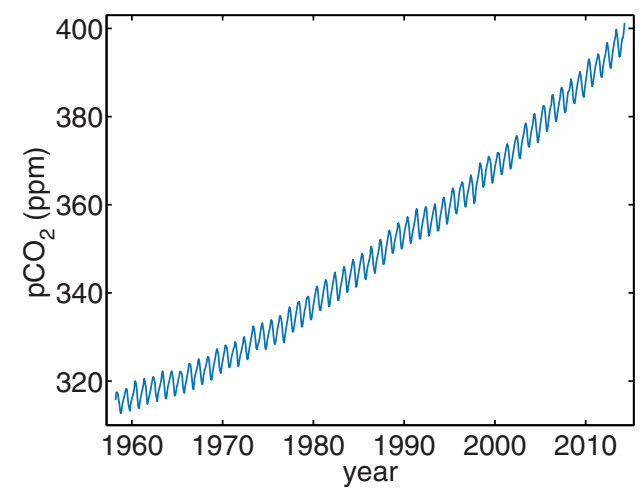

Figure 1. Partial pressure of atmospheric $\mathrm{CO}_{2}$ at Mauna Loa Observatory, Hawaii [74]. The oscillatory component represents seasonal imbalances between photosynthesis and respiration.

The leak has another, more profound, consequence. To recognize it, we write the carbon cycle as a chemical reaction:

$$
\mathrm{CO}_{2}+\mathrm{H}_{2} \mathrm{O} \rightleftharpoons \mathrm{CH}_{2} \mathrm{O}+\mathrm{O}_{2} .
$$

The reaction from left-to-right is photosynthesis, via which $\mathrm{CO}_{2}$ is reduced to a schematic carbohydrate $\left(\mathrm{CH}_{2} \mathrm{O}\right)$ and free oxygen is created. The back reaction is respiration: organic matter is oxidized to $\mathrm{CO}_{2}$, consuming the $\mathrm{O}_{2}$ that had been produced by photosynthesis. Now note that if some $\mathrm{CH}_{2} \mathrm{O}$ can exit the cycle and be buried as rock, a corresponding amount of $\mathrm{O}_{2}$ must accumulate elsewhere, notably the atmosphere. The oxygen we breathe thus owes its existence to the leak [10, 19, 33, 36]. So too does the advent of complex multicellular life-animals with aerobic metabolisms - about 550 million years ago [47, roughly three billion years after the origin of life [41.

Earth's carbon cycle therefore plays a major role in determining not only $\mathrm{CO}_{2}$ levels and climate but also life's interaction with the physical environment. Understanding the bigger story - the natural cycle, at all scales of time and spaceprovides a scientific foundation for understanding the consequences of the rising $\mathrm{CO}_{2}$ levels in Figure 1. More generally, it provides a window into the complex interactions between the many components of the natural world.

Mathematics aids the pursuit. The carbon cycle is an unwieldy beast, but when one strips away insignificant complications, manifestations of elementary mathematical concepts emerge. Our focus here is phenomenological. We feature observational data and its mathematical interpretation, with the objective of providing targets for advancing theoretical understanding. Two types of problems receive special attention. Section 2 is devoted to the problem of decomposition: the processes by which organic matter is converted to $\mathrm{CO}_{2}$. We illustrate ways in which the heterogeneity of the problem can be understood, and we feature scaling laws that appear to result from this heterogeneity. We then discuss problems of dynamics (Section 3), using historical records of past changes to illustrate the scope of the problem. We conclude with an appraisal of the lessons learned and the challenges ahead. 


\section{Decomposition}

After photosynthesis creates organic compounds from $\mathrm{CO}_{2}$, organisms proceed to decompose those compounds to gain energy. As a result, the organic carbon decays. The process plays out at all scales of space and time and in all environments suitable for life. Surprisingly, a common structure emerges despite intrinsic heterogeneity.

2.1. Fast time scales, on land. Forests are widely regarded as sinks for $\mathrm{CO}_{2}$. But all that plant matter eventually decays, providing a $\mathrm{CO}_{2}$ source. How can we characterize the decay? Typical studies measure the dry mass of carbon, $g(t)$, in a reasonably controlled setting. We proceed to consider the example of "litter bags" 30. of plant matter left on the ground over a period of years.

Figure 2(a) shows data obtained from one such experiment. To understand the data, consider first a simple model where $\dot{g}=-k g$, with $k$ a rate constant dependent upon the plant matter composition, environmental conditions, and the microbial community. The resulting exponential decay would imply a straight line in Figure 2(a). However the data in Figure 2(a) do not appear to describe a straight line, suggesting that the simple model is inadequate.

Another approach [15], sometimes referred to as disordered kinetics [58, 61, 76, proceeds from an assumption of heterogeneity. Some bits of a leaf may decay slowly, other bits quickly. This reasoning suggests the existence of a probability density function $p(k)$ of decay constants. Linear superposition then yields the decay

$$
\frac{g(t)}{g(0)}=\int_{0}^{\infty} p(k) e^{-k t} \mathrm{~d} k .
$$

In other words, decay is characterized by the Laplace transform of $p(k)$. In principle, the inverse Laplace transform of $g(t)$ provides $p(k)$. Because this inverse problem is ill-posed, solutions are found by regularization [25].

Figure 2(b) shows the distribution of rate constants that characterize the decay in Figure2(a), plotted as $\rho(x)=p[k(x)] \mathrm{d} k / \mathrm{d} x$, where $x=\ln k$. The result is clearly consistent with a Gaussian, suggesting that $p(k)$ is lognormal with parameters $\mu$ and $\sigma^{2}$ representing the mean and variance, respectively, of $\ln k$. Figures 2 (c) and 2 (d) show the average of 182 different solutions, for different plant matter in different forests throughout North America, each rescaled to have zero mean and unit variance on the $\ln k$ axis. The result is again Gaussian, suggesting that a lognormal distribution of time scales is a general characteristic of plant-matter decay.

Why is the lognormal ubiquitous? The simplest answer appeals to unspecified multiplicative processes and the central limit theorem [6]. A more mechanistic interpretation derives from the following argument [25, 51,69]. We suppose that the decay of a particular component of plant matter requires the satisfaction of various conditions, such as the presence of water, the presence of a specific micro-organism, the expression of particular enzymes, etc. Then if the probability $P$ of decomposing that component during a small time $\Delta t$ is the product of independent probabilities of satisfying many requirements, the rate constant $k=P / \Delta t$ is lognormal.

This natural manifestation of the central limit theorem, a kind of elementary universality 38, suggests a common form of plant-matter decay. The parameters $\mu$ and $\sigma$ turn out to be related to climatic conditions and the composition of the plant matter 25]. To understand their practical importance, consider first the 

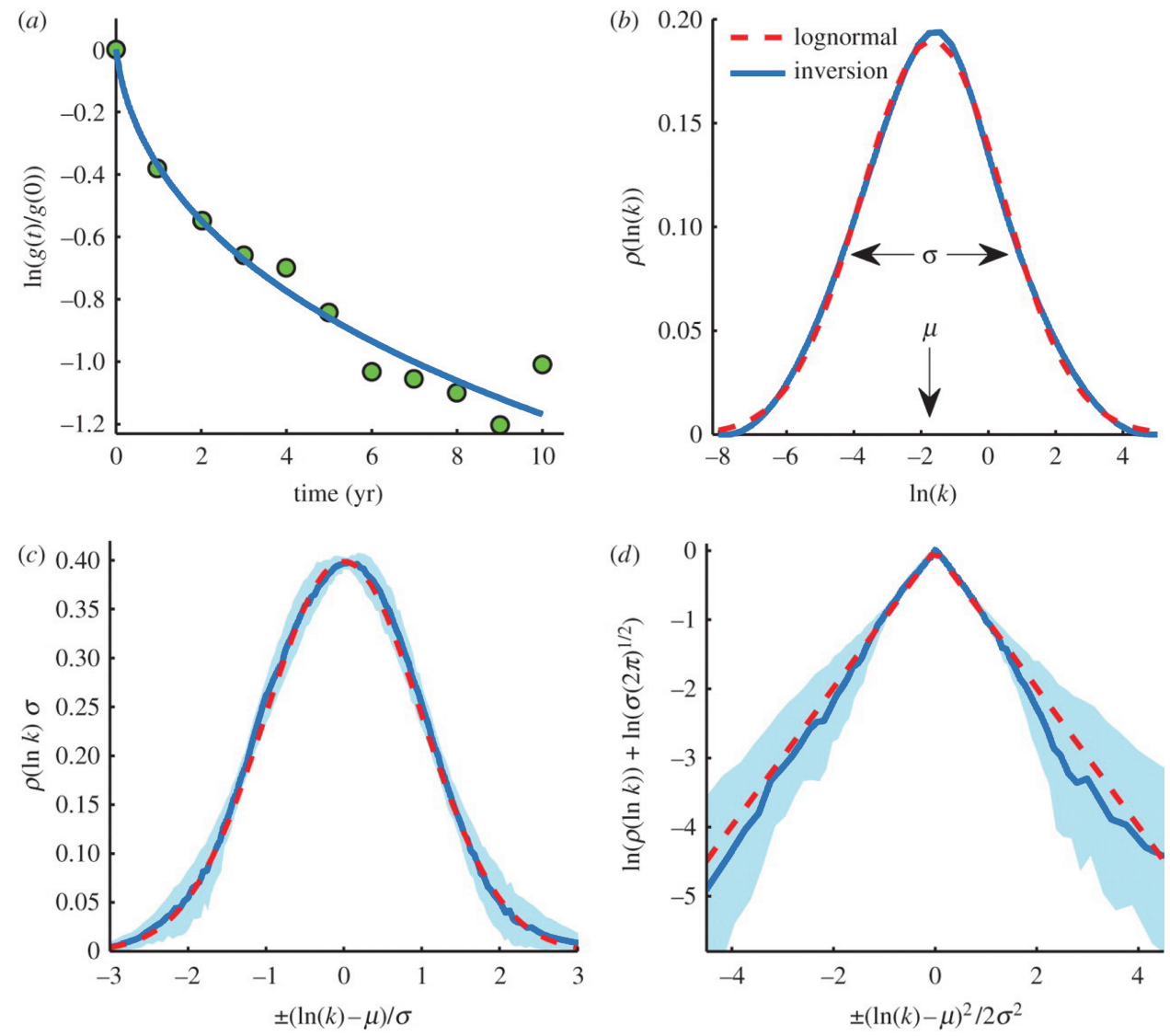

FiguRE 2. Analysis of plant-matter decay 25. (a) Experimental results from a single sample. The smooth curve is the Laplace transform of the solid (blue) curve in (b). (b) The solid curve (blue) is the solution $\rho(\ln k)$ obtained by inversion of the data in (a). The dashed curve (red) is the best-fitting Gaussian, with variance $\sigma^{2}$ and mean $\mu$. (c) The solid curve (blue) is the average of 182 rescaled solutions $\rho(\ln k)$. The dashed curve (red) is a Gaussian with zero mean and unit variance; the shaded area represents the scatter of solutions. (d) Logarithmic transformation of the results of (c). The dashed (red) straight lines indicate an exact lognormal distribution.

average rate constant

$$
\langle k\rangle=\int_{0}^{\infty} k p(k) \mathrm{d} k,
$$

which is also the apparent rate constant $\dot{g} / g$ at $t=0$. Inserting the lognormal distribution for $p(k)$, we find

$$
\langle k\rangle=e^{\mu+\sigma^{2} / 2} .
$$


One might think that the inverse of the mean rate, $\langle k\rangle^{-1}$, would estimate the mean lifetime of organic matter. But it does not; the average time to decay is instead the turnover time $\tau=\left\langle k^{-1}\right\rangle$. When $p(k)$ is lognormal [25],

$$
\tau=e^{-\mu+\sigma^{2} / 2}=\langle k\rangle^{-1} e^{\sigma^{2}} .
$$

We see that the mean lifetime $\tau$ equals $\langle k\rangle^{-1}$ only when $\sigma=0$; otherwise $\tau$ increases exponentially with $\sigma^{2}$. Typical values of $\sigma$ for plant-matter decay range from about $1-2[25]$.

2.2. Intermediate time scales, at sea. About half of annual photosynthetic primary production occurs at sea, in the upper hundred meters of the ocean where sunlight penetrates 37. About $90 \%$ of the production is consumed in those shallow waters. The remainder sinks, over a time scale of about a month, during which about $90 \%$ of the sinking fraction is consumed [34].

There are about 700 gigatons (Gt) of organic carbon in the oceans [37, which presumably represents a steady-state balance between production and respiration. Nearly all of the organic matter in the oceans is effectively dissolved [29]. Each year, about $50 \mathrm{Gt}$ of carbon are fixed by marine photosynthetic organisms. The assumption of a steady state then allows the turnover time of marine organic carbon to be straightforwardly calculated:

$$
\tau=\frac{700 \mathrm{Gt}}{50 \mathrm{Gt} / \mathrm{yr}}=14 \mathrm{yr} .
$$

Modern radiocarbon methods provide an estimate of the mean age of the dissolved phase. The mean age turns out to be about 5000 yr [21, more than 300 times greater than the mean lifetime $\tau$ ! What happened?

To gain insight, we imagine that the same model (2.1) of disordered kinetics that describes terrestrial plant-matter decay also applies to the oceans, and seek an expression for the mean age in a steady state characterized by a constant input of fresh organic matter. Taking $a$ to be the age of a parcel of organic carboni.e., the duration of time since its photosynthetic creation - the steady-state age distribution $p_{a}(a)$ is given by 13

$$
p_{a}(a)=\frac{\left\langle e^{-k a}\right\rangle}{\left\langle k^{-1}\right\rangle} .
$$

Here angle brackets again represent averages taken with respect to $p(k)$; thus the numerator represents the fraction of organic carbon that survives decay until age $a$. The mean age $\bar{a}=\int_{0}^{\infty} a p_{a}(a) \mathrm{d} a$; thus 1

$$
\bar{a}=\frac{\left\langle k^{-2}\right\rangle}{\left\langle k^{-1}\right\rangle} .
$$

If $p(k)$ is lognormal,

$$
\bar{a}=\tau e^{\sigma^{2}}
$$

showing that the ratio of the mean age to the turnover time increases exponentially with the variance of $\ln k$. Taking $\tau=14 \mathrm{yr}$ and $\bar{a}=5000 \mathrm{yr}$, we obtain $\sigma=2.4$, roughly consistent with that found for plant-matter decay. Although the

\footnotetext{
24 .

${ }^{1}$ For an alternative derivation using the von Foerster equation of population dynamics [53], see
} 
assumption of lognormality remains untested for the marine problem, this calculation makes clear that, if indeed equation (2.1) applies, long-tailed rate distributions can produce huge disparities between the mean age of a reservoir and its mean lifetime. In this respect, it may be useful to note that if decay is characterized by a single rate $k_{0}$ with no dispersion, then $\bar{a}=\tau=k_{0}^{-1}[13$. Discrepancies between age and turnover time are therefore a quantitative signature of the kinetic complexity of the carbon cycle.

2.3. Slow time scales, in sediments. The $1 \%$ of marine primary production that survives decay long enough to settle on the seafloor may nevertheless be degraded within sediment. How that process evolves is a subject of much discussion and debate [35. There is, however, some observational certainty: the longer a parcel of organic matter survives, the slower its decay becomes. Remarkably, this aging process is characterized by an empirical scaling law.

The scaling law concerns the evolution of the effective first-order rate constant

$$
k_{\text {eff }}=-\frac{\mathrm{d} \ln g}{\mathrm{~d} t} .
$$

Over time scales ranging from days to millions of years, observations suggest [48, 49] that

$$
k_{\text {eff }} \propto t^{-1} .
$$

Perhaps the simplest way of understanding this observation is to appeal again to multiplicative processes and lognormal disordered kinetics. We approximate the lognormal as a uniform distribution in $\log$ space, such that $\rho(\ln k)$ is constant and $p(k) \propto 1 / k$ between minimum and maximum rates $k_{\min }$ and $k_{\max }$, respectively. This "log-uniform" approximation is valid when $(\ln k-\mu) / 2 \sigma^{2} \ll 1[51$. Inserting it into (2.1), we find

$$
g(t) / A \sim E_{1}\left(k_{\min } t\right)-E_{1}\left(k_{\max } t\right),
$$

where $E_{1}(x)=\int_{1}^{\infty} k^{-1} e^{-k t} \mathrm{~d} k$ is the exponential integral [7] and $A$ is a constant. When $k_{\text {max }} \gg k_{\min }$, the second exponential integral can be neglected at log times $t \gg 1 / k_{\max }$. An asymptotic expansion [7] of the first integral for $t \ll k_{\min }^{-1}$ then yields 62 .

$$
g\left(k_{\min } t\right) \sim-\gamma-\ln k_{\min } t, \quad k_{\max }^{-1}<t \ll k_{\min }^{-1},
$$

where $\gamma=0.5772 \cdots$ is Euler's constant. Equation (2.12) fits much observational data 62. Inserting it into (2.9), we reproduce the $1 / t$ scaling of equation (2.10) with a weak logarithmic correction 62 .

2.4. Immobilization. As already indicated in the Introduction, a small fraction of organic matter-about $0.1 \%$ - escapes decay. Informally, one says it is buried; more accurately, it is immobilized deep within sediment where it can no longer be degraded. Such a slow process would naively seem to be insignificant. Yet, as stated above, this small leak out of the carbon cycle is directly responsible for the oxygenation of the atmosphere [10, 19, 33, 36].

Astonishingly, observational data suggest the existence of another scaling law. The quantity of interest is the immobilized fraction

$$
\phi=\frac{\text { mass of organic carbon immobilized }}{\text { mass of organic carbon entering sediments }},
$$




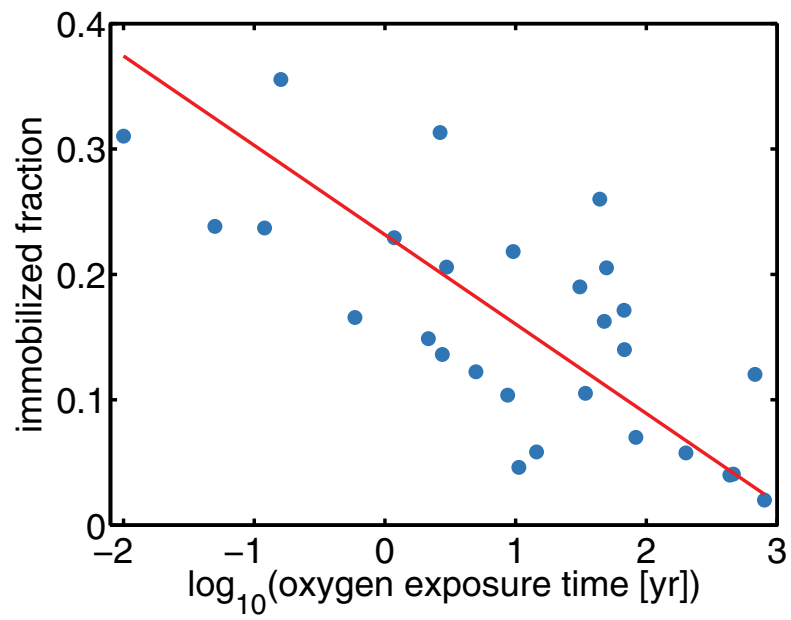

Figure 3. The immobilization fraction $\phi$ as a function of the logarithm of the oxygen exposure time $t_{\mathrm{ox}}$ [31] compared to the bestfitting straight line. The measurements are obtained from analyses of ocean-bottom sediments. Further evidence of the logarithmic time dependence can be found in 27.

also called the "burial efficiency" [11. Typically, $\phi \sim 0.1$. There is, however, significant natural variability.

One cause of variability relates to the existence of oxygen in the sedimentary environment. Most seafloor environments are oxic. However $\mathrm{O}_{2}$ penetrates only to shallow depths (typically $1-10 \mathrm{~mm}$ beneath the sediment-water interface [31]) because it is consumed by microbes feeding on detritus. Once $\mathrm{O}_{2}$ is depleted, anaerobic microbial communities continue to consume the remaining organic matter in deep sediments. However, there is growing evidence that some kinds of organic matter - or organic matter that is physically protected by its association with mineral surfaces 40 - can be degraded only in the presence of $\mathrm{O}_{2}$ 31. This observation may derive from a unique ability of aerobic micro-organisms to manufacture the hydrolytic enzymes and/or other chemical agents required for degradation of otherwise inert organic matter.

Figure 3 supports this picture. Here the immobilized fraction $\phi$ is plotted as a function of the logarithm of the oxygen exposure time $t_{\mathrm{ox}}$ [31. The time $t_{\mathrm{ox}}$ is calculated by dividing the depth (beneath the seafloor) of $\mathrm{O}_{2}$ penetration by the rate at which sediment is deposited on the seafloor. A remarkably simple result appears to emerge: $\phi$ decreases linearly with $\log t_{\mathrm{ox}}$ 31.

This observation can be understood in terms of the following reaction-diffusion problem 62, 75. Aerobic microbes emit a constant flux of enzymes that diffuse away. The enzymes hydrolyze organic matter upon contact, but eventually enzymes become inactive. Under the assumptions that the consumption of organic matter is limited by hydrolysis and that hydrolysis is diffusion limited, the steady-state concentration of enzymes is inhomogeneously distributed in space. The probability of finding a particular concentration $c$ of enzymes at a given location is then found to scale approximately like $1 / c$ within wide limits. If we assume that the degradation 
proceeds locally at a rate proportional to $c$, we derive once again the logarithmic decay of equation (2.12), where $k_{\text {min }}$ is related to the characteristic distance between microbes 62].

Note, however, that we have just described decay, not preservation. To understand preservation, we assume, following Hedges and Keil 35, that there are two kinds of organic matter: that which is only degraded aerobically and that which will always eventually degrade anaerobically. The quantity $\phi\left(t_{\mathrm{ox}}\right)$ therefore represents the decay of the portion that requires the oxic environment, as a function of the time $t_{\mathrm{ox}}$ of exposure to that environment. We therefore find, as with (2.12),

$$
\phi\left(t_{\mathrm{ox}}\right) \simeq \text { const. }-\log t_{\mathrm{ox}}
$$

consistent with Figure 3 .

2.5. Logarithmic time. The models discussed above provide rationalizations of the kinetic complexity of the carbon cycle. Collectively, they suggest that the carbon cycle's back reaction-respiration - follows the rhythm of a logarithmic clock. That is, equal amounts of organic carbon are converted to equal amounts of $\mathrm{CO}_{2}$ during equal amounts of the logarithm of time since the organic carbon was produced. In this way, local microbial metabolisms acting on biological time scales exert an influence globally at geologic time scales. The fast and slow processes of the carbon cycle then appear as two ends of a continuum, in some ways more alike than they are different.

\section{DYNAMiCS}

The analyses of Section 2 provide a basis for understanding and specifying rates of global respiration. Such rates are required for parameterizing models of the form 26

$$
\dot{x}=j_{i}-j_{o},
$$

where, for example, $x$ represents the mass of $\mathrm{CO}_{2}$ in the atmosphere, and $j_{i}$ and $j_{o}$ represent fluxes of $\mathrm{CO}_{2}$ into the atmosphere (e.g., respiration and fossil fuel burning) and fluxes out (e.g., primary production and absorption into the oceans), respectively. A basic problem concerns feedbacks; i.e., the dependence of the fluxes on $x$. For example, if the climate becomes warmer, frozen ground in the arctic will thaw, exposing ancient organic matter to decomposition [79]. Consequently, $\mathrm{CO}_{2}$ levels would rise, leading to more warming, etc. On the other hand, the same processes lead to more primary production due to the release of nutrients, causing more carbon to be stored in, say, new forest growth. Which flux will dominate?

Answering such questions is crucially important for understanding the carbon cycle's dynamics, including the identification of steady states, the specification of rates of relaxation towards those steady states, and the analysis of stability. Here we illustrate these issues by considering examples of dynamical change in the modern and ancient carbon cycle.

3.1. Impulse response. The rising $\mathrm{CO}_{2}$ levels in Figure 1 motivate a simple question. If we inject, say, 1 gigaton of carbon in the atmosphere today, how does the system respond to this impulse?

In the 1950s and early 1960s, tests of nuclear weapons produced a significant increase in the concentration of ${ }^{14} \mathrm{C}$ in the atmosphere. The tests were essentially ended by the Nuclear Test Ban Treaty in October 1963. Figure 4 shows that the 

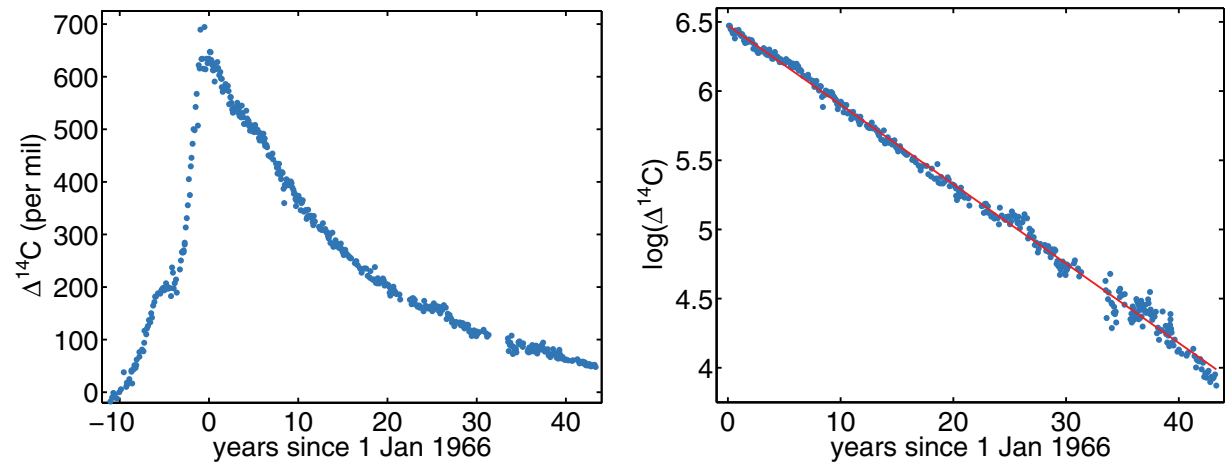

Figure 4. Evolution of ${ }^{14} \mathrm{C}$ in the atmosphere [20. The quantity plotted, $\Delta^{14} \mathrm{C}$, is effectively proportional to the atmospheric ${ }^{14} \mathrm{C}$ concentration minus a baseline concentration. Left: $\Delta^{14} \mathrm{C}$ as a function of time. Right: $\log \left(\Delta^{14} \mathrm{C}\right)$ as a function of time, compared to a straight line, showing that the decay is exponential. The slope corresponds to the best-fitting time constant, about $17 \mathrm{yr}$.

${ }^{14} \mathrm{C}$ content of the atmosphere then decayed exponentially, like $e^{-\omega \tau}$, where the time constant $\omega^{-1} \simeq 17$ yr.

Although ${ }^{14} \mathrm{C}$ is an unstable isotope of carbon, its half-life, about $5730 \mathrm{yr}$, is far too large to account for the exponential decay. The exponential decay instead largely represents the equilibration of the atmospheric ${ }^{14} \mathrm{C}$ concentration with that of the ocean. Using the "thin-film" model of Broecker and Peng [16, one considers the ocean to be in a pre-existing steady-state balance between the input of "natural" ${ }^{14} \mathrm{C}$ from the atmosphere and its radioactive decay to ${ }^{12} \mathrm{C}$. The so-called bomb spike of ${ }^{14} \mathrm{C}$ then diffuses into the ocean through a thin boundary later at the sea surface. Such a simple model predicts not only the exponential decay but it also provides a reasonable estimate of the time constant.

The decay of the bomb spike presents the simplest example of a global impulse response in the carbon cycle. But it provides only a partial view of the problem, not only because of the short time scale, but also because ${ }^{14} \mathrm{C}$ is effectively a passive tracer with an inconsequential concentration. The reality is vastly more complicated - and more interesting [1,3]. As $\mathrm{CO}_{2}$ is absorbed into the oceans, the oceans become more acidic, which makes the oceans increasingly less able to absorb more $\mathrm{CO}_{2}$. This results in a new equilibrium state, on a time scale of about 200$2000 \mathrm{yr}$, characterized by a 20-35\% net increase in atmospheric $\mathrm{CO}_{2}$ levels. At longer time scales, slow geochemical processes act to restore, or nearly restore, the original equilibrium.

3.2. Stability. The persistence of elevated $\mathrm{CO}_{2}$ levels despite absorption into the oceans suggests not only that perturbations need not fully decay, but also that nonlinearities within the carbon cycle could conceivably amplify a perturbation. Indeed, the geologic record contains much evidence of past disturbances in the carbon cycle. Whether these result from internal excitations or external forcings remains a question. We proceed to review some examples. 


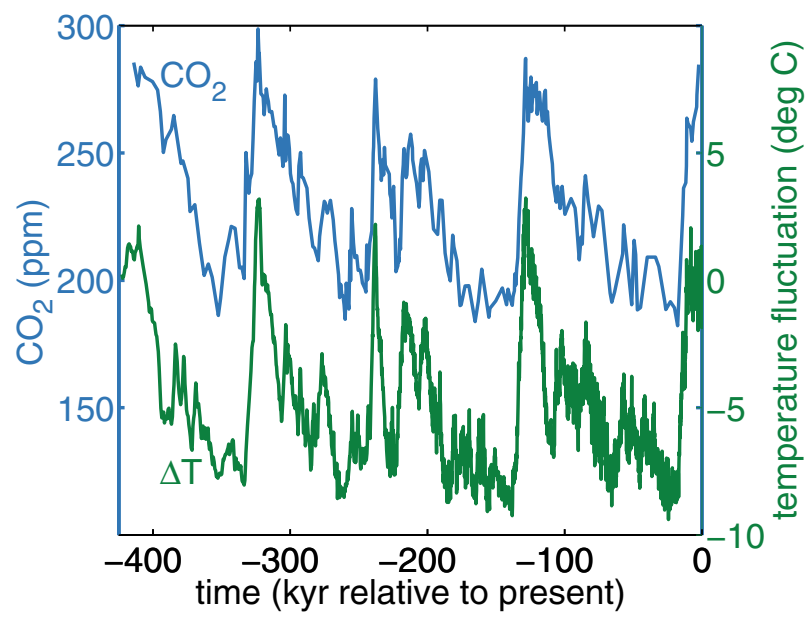

FiguRE 5. Fluctuations of the atmospheric $\mathrm{CO}_{2}$ concentration (blue upper curve) and temperature (green lower curve) in Antarctica for the last 420,000 years, obtained from analyses of the Vostok ice core 56 .

3.2.1. Glacial cycles. Figure 5 displays one of the most fascinating - and enigmatic - datasets in climate science: the fluctuations of atmospheric $\mathrm{CO}_{2}$ concentrations and surface temperature in Antarctica for the last 420,000 years, obtained from the Vostok ice core [56]. Two features immediately capture one's attention: the $\sim 100,000$ yr periodicity of the fluctuations, and the extraordinarily tight correlation of the two signals.

The periodicity of the glacial cycles is widely considered to be due to variations in Earth's orbital parameters [52]. (For an alternative view, see [78.) The eccentricity of Earth's orbit varies slightly, between about 0 and 0.05 , with a period of about $100 \mathrm{Kyr}$. Earth's spin axis precesses with a period of about $26 \mathrm{Kyr}$, and the tilt, or obliquity, of the spin axis varies with a period of about $41 \mathrm{Kyr}$. Neither the changes in obliquity nor the changes in precession have any effect on the total annual flux of solar energy received by Earth. However, changes in eccentricity change the annually averaged distance from the sun; consequently, eccentricity directly influences annually averaged insolation (the solar radiation energy received per unit area). One would therefore be tempted to immediately ascribe the 100 Kyr periodicity of the temperature record in Figure 5 to the eccentricity variations. However, the perturbation of insolation due to changes in eccentricity varies to leading order like eccentricity squared [8]; the resulting small change cannot by itself account for the climatic shifts. Many treatments of the problem, beginning with the original hypothesis of Milankovič [50], suggest that the controlling variable is not global insolation but instead the insolation in the northern hemisphere, where most glacial ice is located. For example, [22] demonstrates an impressive correlation between insolation at the summer solstice (derived from obliquity and eccentricity variations) and the derivative of the global ice volume (inferred from geochemical measurements). 
Whatever the role of the orbital changes in the glacial cycles, there remains the question of what drives the synchronous changes in atmospheric $\mathrm{CO}_{2}$ concentrations [4,70]. Because there is no reason to imagine that the orbital changes directly affect $\mathrm{CO}_{2}$, it would appear that $\mathrm{CO}_{2}$ levels are in some sense responding to the climatic changes. For example, because $\mathrm{CO}_{2}$ is more soluble in colder water, the oceans must absorb more $\mathrm{CO}_{2}$ during glacial climates. Correspondingly, atmospheric $\mathrm{CO}_{2}$ concentrations must decline, by about $30 \mathrm{ppm}$ [70, which is only about one-third of that seen in Figure 5. On the other hand, we know that declining $\mathrm{CO}_{2}$ levels should result in cooler climates [57; thus it seems likely that the changes in the carbon cycle and climate are amplifying each other to produce the glacial cycles of Figure 5. Consequently, the carbon cycle, when suitably forced, contains within it mechanisms for losing the stability of its steady state at time scales of $10^{4}-10^{5}$ yr [2. Moreover, the extraordinary synchronization and apparent periodicity of the two signals in Figure 5 suggest that whatever the feedback mechanisms are, they are simple enough to be reliably repeatable.

3.2.2. Long-term evolution. Figure 6 is a record of the carbon cycle's fluctuations at the longest possible time scales, from 3.8 billion years ago (approximately the time of the origin of life [14,65]) to present. This record contains evidence of both stability and instability. To see why, we first digress to explain the quantity plotted.

Carbon occurs as two stable isotopes, ${ }^{12} \mathrm{C}$ and ${ }^{13} \mathrm{C}$. However the relative partitioning of ${ }^{12} \mathrm{C}$ and ${ }^{13} \mathrm{C}$ in different global "reservoirs" need not be constant. In

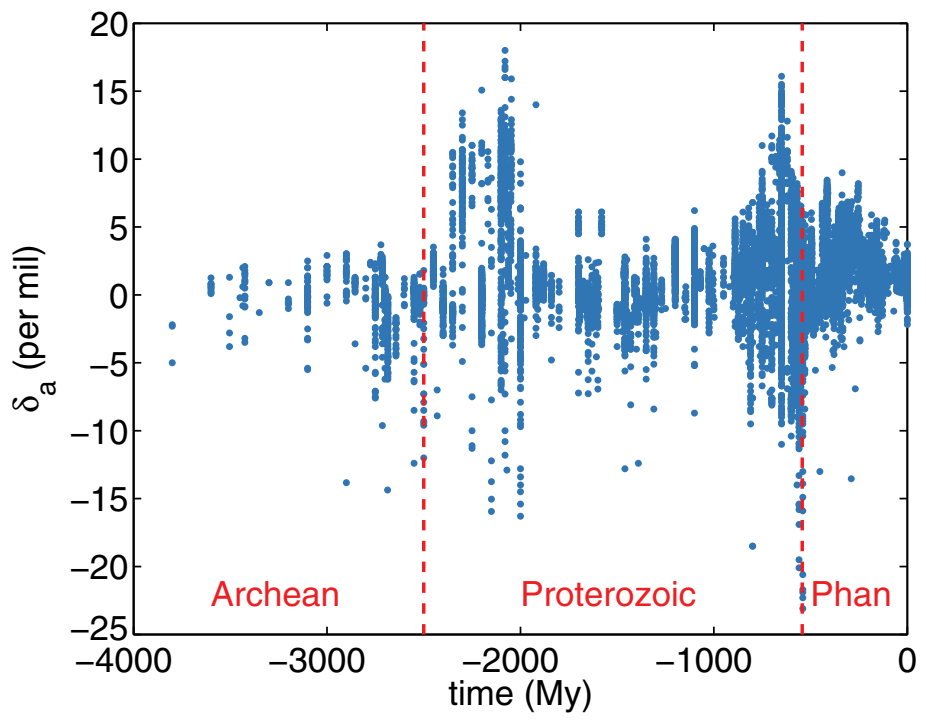

FiguRE 6. Evolution of the carbon isotopic composition of carbonate rocks for the last 3.8 billion years 68. The red dashed lines demarcate the Archean, Proterozoic, and Phanerozoic eons. The large fluctuations at the beginning and end of the Proterozoic may be associated with the early and late stages, respectively, of the oxygenation of the atmosphere. The later set of fluctuations immediately precedes the evolution of complex, multicellular life. 
particular, the production of organic carbon from $\mathrm{CO}_{2}$ by photosynthesis slightly favors the lighter isotope, so that organic carbon contains a smaller fraction of ${ }^{13} \mathrm{C}$ than the $\mathrm{CO}_{2}$ from which it was produced [32. In Section 2.4 we discussed the long-term immobilization of organic carbon in rocks. Inorganic carbon is also sequestered in rock, as carbonate. If the carbon cycle is in a steady state where the average isotopic composition of carbon in the Earth's surface environment is constant, the depletion of ${ }^{13} \mathrm{C}$ in organic carbon requires that inorganic carbon be relatively enriched. Geochemists measure these quantities in terms of the departure of the abundance ratio $R_{x}=\left({ }^{13} \mathrm{C} /{ }^{12} \mathrm{C}\right)_{x}$ for carbon of type $x$. Such isotopic data is then reported in terms of the departure of this ratio from a standard ratio $R_{\text {std }}$ as the quantity

$$
\delta_{x}=\frac{R_{x}-R_{\text {std }}}{R_{\text {std }}} \times 1000,
$$

where multiplication by 1000 means that the units are parts per thousand, or per mil. Figure 6 is a plot of this quantity over geologic time, for carbonate (inorganic) carbon, signified by $\delta_{a}$. That the average value of $\delta_{a}$ is near zero reflects the choice of $R_{\text {std }}$.

There is also an analogous measure for organic carbon, $\delta_{o}$ (not shown), which for present purposes may be taken to be less than $\delta_{a}$ by a constant. Because the relative abundance of ${ }^{13} \mathrm{C}$ is much smaller than that of ${ }^{12} \mathrm{C}$, the abundance of ${ }^{12} \mathrm{C}$ approximates the abundance of all carbon, so that the average isotopic composition $\bar{\delta}$ of all carbon can be expressed as 32 ]

$$
\bar{\delta}=(1-f) \delta_{a}+f \delta_{o}, \quad 0 \leq f \leq 1,
$$

where $f$ is the fraction of buried carbon that is organic.

With these details out of the way, we can now arrive at two simple yet profound interpretations of Figure 6. The first is to identify the characteristic value of $\delta_{a}$ with a characteristic value of the organic burial fraction $f$. One find: $f \simeq 0.2[32$; thus for every five moles of carbon that are sequestered as rock, one is organic and four are inorganic. There has been a tendency to regress to this 1:4 ratio - the essential stoichiometry of the long-term carbon cycle - ever since the origin of life. Neither the value of the ratio nor its long-term stability have been explained.

Somehow the stoichiometry has remained approximately constant despite tremendous changes in both the biosphere and geosphere. Among the most important of those changes is the oxygenation of the atmosphere and oceans. Various lines of evidence suggest that the initial rise of oxygen occurred around 2.4 billion years ago [19]. Because larger, multicellular organisms with aerobic metabolisms evolved nearly two billion years later [41, it is thought that a second rise in oxygen occurred around 600 million years ago [54]. These two periods bookend the Proterozoic eon in Figure 6. As discussed in Sections 1 and 2.4 the carbon cycle is intimately connected to the accumulation of oxygen via the immobilization of organic matter. Thus it is tempting to identify the large fluctuations in $\delta_{a}$ at the beginning and end of the Proterozoic with periods of instability in the carbon cycle. Dynamical systems passing through a bifurcation may be expected to exhibit large fluctuations [45]. Possibly one or both periods of relative instability in Figure 6] represent such changes 64.

\footnotetext{
${ }^{2}$ Typically, $\bar{\delta}=-6$ per mil and $\delta_{a} \simeq 0$ per mil. The fraction $f \simeq 0.2$ results from assuming that $\delta_{o}$ is about 30 per mil smaller than $\delta_{a}$.
} 
This brings us to a conundrum. The logarithmic relation between immobilization and oxygen-exposure time (Figure 3) can be interpreted as a negative feedback for $\mathrm{O}_{2}$. That is, as $\mathrm{O}_{2}$ levels increase, so too does oxygen exposure time, and thus $\mathrm{O}_{2}$ "production" (proportional to the immobilized fraction when all else is constant) decreases [31. How then, could $\mathrm{O}_{2}$ levels have increased from a state that was already stable? Possibly, the early rise in $\mathrm{O}_{2}$ was controlled by different mechanisms 33, one of which has been described as a saddle-node bifurcation 28. The late-Proterozoic rise, however, almost surely has some relation to carbon burial [19,54], suggesting that the dependence of burial on $\mathrm{O}_{2}$ may not be as simple as that depicted by Figure 3. Alternatively, the controls on $\mathrm{O}_{2}$ production or consumption may have changed over geologic time, possibly in a way that implies a second bifurcation in the late Proterozoic [46. Whatever the case, one is left wondering why the burial fraction $f$ has apparently remained constant since the origin of life. Conceivably, the mass balance of equation (3.3) requires greater complexity to reliably interpret the lack of long-term isotopic change in Figure 66 66.

3.2.3. End-Permian extinction. The oxygenation of Earth's surface environmentand the accompanying changes in the carbon cycle - made possible the evolution of complex multicellular life about 550 million years ago. The biosphere's ensuing evolution, however, is not stable. It is instead punctuated by periods of mass extinction [59] accompanied by disruptions of the carbon cycle [77. Here we illustrate this point for the most severe crisis in the fossil record: the end-Permian extinction [23].

Figure $7(\mathrm{~A})$ shows the changes in the isotopic composition of inorganic $\left(\delta_{a}\right)$ and organic $\left(\delta_{o}\right)$ carbon immediately preceding the extinction. A severe perturbation of the carbon cycle is reflected in the accelerating decline of $\delta_{a}$, which spans about 60,000 years [17. The ensuing period of extinction (not shown) also lasts about 60,000 years [17.

The cause of the carbon cycle's disruption remains mysterious, but it is widely viewed to result from the injection of isotopically light carbon into the oceans 23 , 44, 67. Making this assumption, one can transform the geochemical data of Figure 7(A) to the accumulated excess mass $M(t)$ of marine inorganic carbon [63]. The result, shown in Figure $7(\mathrm{~B})$, suggests that $M(t)$ grows like the singular blow-up

$$
M(t) \propto \frac{1}{t_{c}-t},
$$

where the blow-up time $t_{c}$ is coincident with the initiation of the extinction 63 . This observation implies that the end-Permian carbon cycle underwent an instability dominated by a quadratic nonlinearity; i.e., $\dot{M} \sim M^{2}$. Because $t_{c}$ would derive from initial conditions, the time of extinction would have been set by the size and time of the initial perturbation.

What caused the disruption of the carbon cycle? Massive Siberian volcanism likely occurred at the same time [60] however, the magnitude of the isotopic shift appears larger than that which would be predicted by volcanic $\mathrm{CO}_{2}, 9,67$. Possibly volcanism remobilized isotopically light carbon buried in Siberian sediments 55, 73 , but such a scenario appears inconsistent with the singular growth of equation (3.4) 63]. Reference 63] suggests an alternative hypothesis: the emergence of a new microbial pathway that efficiently converted sedimentary organic carbon 

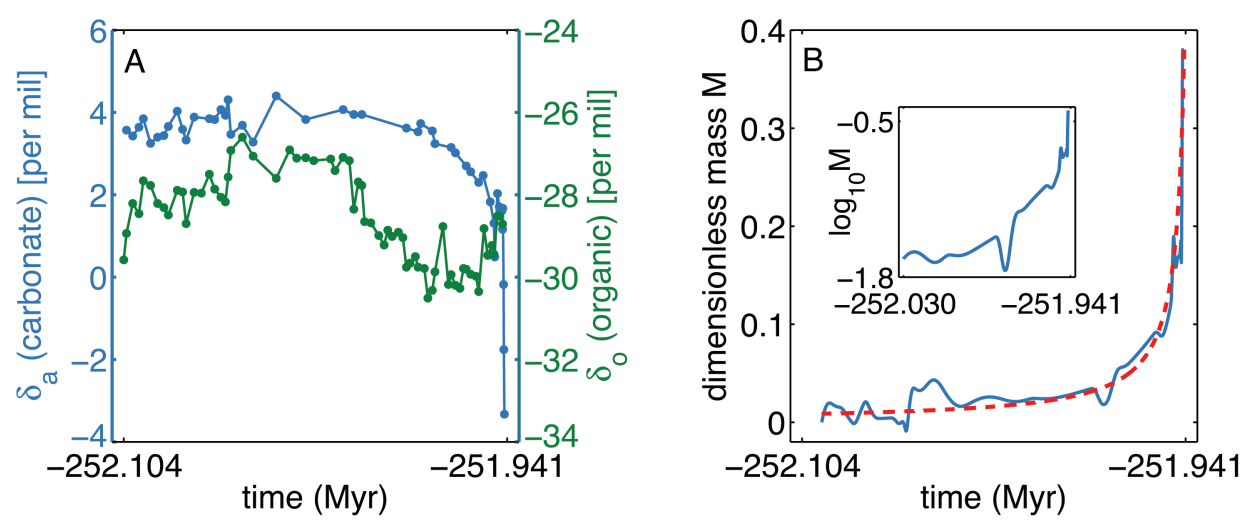

FiguRE 7. (A) Evolution of the carbon isotopic composition of inorganic (carbonate) and organic carbon in late-Permian sedimentary rocks at Meishan, China [18. The dates shown have been determined with an accuracy of about $0.02 \%$ [17. The end-Permian extinction begins immediately after the sharp downturn of the carbonate curve, 251.941 million years ago. (B) Transformation of the geochemical signals in (A) to the accumulated mass $M(t)$ of isotopically light carbon added to the oceans (smooth blue curve), normalized with respect to the mass prior to perturbation. The red dashed line indicates the singular blow-up of equation (3.4). The curvature of the semi-logarithmic plot in the inset suggests that the growth of $M(t)$ is faster than exponential, further supporting the fit to the singular blow-up. Modified from 63 .

to methane. The success of the new pathway would have led to the unstable expansion of its ecological niche and the growth of $\mathrm{CO}_{2}$ production (by oxidation of the methane) consistent with equation (3.4). Ocean acidification would have then caused the marine extinction [42,43].

Such interpretations are of course speculative. Nevertheless, the association of an instability in the carbon cycle with the greatest extinction in Earth history suggests that the rising $\mathrm{CO}_{2}$ levels of Figure 1 may affect far more than our climate.

\section{Conclusion}

Much attention in climate science is focused on the response of climate to changes in $\mathrm{CO}_{2}$ levels. A major unknown, however, is the biosphere's response. Does it amplify changes in $\mathrm{CO}_{2}$, damp them out, or remain neutral? And at what time scale? These questions address the need to develop a deeper understanding of the carbon cycle, from which we may then better predict the consequences of the trend in Figure 1,

To a considerable extent, the problem is observational. That is, a better understanding of the carbon cycle will follow from more observations of its past and present behavior. Data, however, require understanding. This review has focused on observational data that have been, or appear likely to be, understood by mathematical theory. 
An important lesson emerges: despite the carbon cycle's complexity, it exhibits behavior that is simple enough to comprehend mathematically. Such mathematical understanding then leads to basic insights. For example, the apparent universality of the lognormal rate distribution suggests a new interpretation of plant-matter decay: rather than being a collection of special cases, the decay of leaves becomes a manifestation of general principles. We also learn how to relate kinetics at small scales of space and time to long-term global fluxes.

Much remains to be done. Because the carbon cycle represents the coupling between life and the environment - metabolism at a global scale - its mathematical description inherits the difficulties of biology in addition to physical science. Thus, theoretical understanding of dynamics, so crucial to advancing knowledge of how the carbon cycle works, remains more qualitative than quantitative. Such problems present scientific opportunities with no shortage of social significance. Mathematics will surely play a central role in future progress.

\section{AbOUt THE AUTHOR}

Daniel H. Rothman is a professor of geophysics at Massachusetts Institute of Technology. He codirects MIT's Lorenz Center, which is devoted to learning how climate works.

\section{References}

[1] D. Archer, The long thaw, Princeton University Press, Princeton, N.J., 2009.

[2] D. Archer, The global carbon cycle, Princeton University Press, Princeton, N.J., 2010.

[3] D. Archer, M. Eby, V. Brovkin, A. Ridgwell, L. Cao, U. Mikolajewicz, K. Caldeira, K. Matsumoto, G. Munhoven, A. Montenegro, and K. Tokos, Atmospheric lifetime of fossil fuel carbon dioxide, Annual Review of Earth and Planetary Sciences 37 (2009), 117-134 (English).

[4] D. Archer, A. Winguth, D. Lea, and N. Mahowald, What caused the glacial/interglacial atmospheric $\mathrm{COO}_{2}$ cycles?, Reviews of Geophysics 38 (2000), no. 2, 159-189.

[5] S. Arrhenius, On the influence of carbonic acid in the air upon the temperature of the ground, The London, Edinburgh, and Dublin Philosophical Magazine and Journal of Science 41 (1896), no. 251, 237-276.

[6] J. Atchison and J. A. C. Brown, The lognormal distribution, Cambridge University Press, 1963.

[7] C. M. Bender and S. A. Orszag, Advanced mathematical methods for scientists and engineers, McGraw Hill Book Company, New York, 1978.

[8] A. Berger and M. F. Loutre, Precession, eccentricity, obliquity, insolation, and paleoclimates, Long-Term Climatic Variations (J.-C Duplessy and M.-T. Spyridakis, eds.), NATO ASI Series, vol. 122, Springer-Verlag, Heidelberg, 1994, pp. 107-151.

[9] R. A. Berner, Examination of hypotheses for the Permo-Triassic boundary extinction by carbon cycle modeling, Proceedings of the National Academy of Sciences USA 99 (2002), no. $7,4172-4177$.

[10] R. A. Berner, The Phanerozoic carbon cycle: $\mathrm{CO}_{2}$ and $\mathrm{O}_{2}$, Oxford University Press, New York, 2004.

[11] J. N. Betts and H. D. Holland, The oxygen content of ocean bottom waters, the burial efficiency of organic carbon, and the regulation of atmospheric oxygen, Palaeogeography, Palaeoclimatology, Palaeoecology (Global and Planetary Change Section) 97 (1991), 5-18.

[12] T. A. Boden, G. Marland, and R. J. Andres, Global, regional, and national fossilfuel $\mathrm{CO}_{2}$ emissions, Tech. report, Carbon Dioxide Information Analysis Center, Oak Ridge National Laboratory, U.S. Department of Energy, Oak Ridge, TN, 2013, doi 10.3334/CDIAC/00001_V2013.

[13] B. Bolin and H. Rodhe, A note on the concepts of age distribution and transit time in natural reservoirs, Tellus 25 (1973), 58-62. 
[14] T. Bosak, A. H. Knoll, and A. P. Petroff, The meaning of stromatolites, Annual Review of Earth and Planetary Sciences 41 (2012), 21-44.

[15] B. P. Boudreau and B. R. Ruddick, On a reactive continuum representation of organic matter diagenesis, American Journal of Science 291 (1991), 507-538.

[16] W. S. Broecker and T. H. Peng, Gas-exchange rates between air and sea, Tellus 26 (1974), no. 1-2, 21-35 (English).

[17] S. D. Burgess, S. A. Bowring, and S.-Z. Shen, High-precision timeline for Earth's most severe extinction, Proceedings of the National Academy of Sciences 111 (2014), no. 9, 3316-3321.

[18] C. Cao, G. D. Love, L. E. Hays, W. Wang, S. Shen, and R. E. Summons, Biogeochemical evidence for euxinic oceans and ecological disturbance presaging the end-Permian mass extinction event, Earth and Planetary Science Letters 281 (2009), no. 3-4, 188 - 201.

[19] D. C. Catling and M. W. Claire, How Earth's atmosphere evolved to an oxic state: a status report, Earth and Planetary Science Letters 237 (2005), no. 1-2, 1-20.

[20] K. I. Currie, G. Brailsford, S. Nichol, A. Gomez, R. Sparks, K. R. Lassey, and K. Riedel, Tropospheric ${ }^{14} \mathrm{CO}_{2}$ at Wellington, New Zealand: the world's longest record, Biogeochemistry (2009), 5-22.

[21] E. R. M. Druffel, P. M. Williams, J. E. Bauer, and J. R. Ertel, Cycling of dissolved and particulate organic matter in the open ocean, Journal of Geophysical Research 97 (1992), 15639-15659.

[22] S. Edvardsson, K. G. Karlsson, and M. Engholm, Accurate spin axes and solar system dynamics: Climatic variations for the earth and mars, Astronomy and Astrophysics 384 (2002), no. 2, 689-701.

[23] D. H. Erwin, Extinction: How life on Earth nearly ended 250 million years ago, Princeton University Press, Princeton, N.J., 2006.

[24] C. L. Follett, Heterogeneous reservoirs in the marine carbon cycle, Ph.D. thesis, Massachusetts Institute of Technology, 2014.

[25] D. C. Forney and D. H. Rothman, Common structure in the heterogeneity of plant-matter decay, Journal of The Royal Society Interface 9 (2012), no. 74, 2255-2267.

[26] P. Friedlingstein, P. Cox, R. Betts, L. Bopp, W. Von Bloh, V. Brovkin, P. Cadule, S. Doney, M. Eby, I. Fung, et al., Climate-carbon cycle feedback analysis: Results from the C4MIP model intercomparison, Journal of Climate 19 (2006), no. 14, 3337-3353.

[27] Y. Gelinas, J. A. Baldock, and J. I. Hedges, Organic carbon composition of marine sediments: effect of oxygen exposure on oil generation potential, Science 294 (2001), 145-148.

[28] C. Goldblatt, T. M. Lenton, and A. J. Watson, Bistability of atmospheric oxygen and the Great Oxidation, Nature 443 (2006), 683-686.

[29] D. A. Hansell, C. A. Carlson, D. J. Repeta, and R. Schlitzer, Dissolved organic matter in the ocean: A controversy stimulates new insights, Oceanography 22 (2009), 202-211.

[30] M. E. Harmon, W. L. Silver, B. Fasth, H. Chen, I. C. Burke, W. J. Parton, S. C. Hart, and W. S. Currie, Long-term patterns of mass loss during the decomposition of leaf and fine root litter: an intersite comparison, Global Change Biology 15 (2009), no. 5, 1320-1338.

[31] H. E. Hartnett, R. G. Keil, J. I. Hedges, and A. H. Devol, Influence of oxygen exposure time on organic carbon preservation in continental margin sediments, Nature 391 (1998), 572-574.

[32] J. M. Hayes, H. Strauss, and A. J. Kaufman, The abundance of ${ }^{13} C$ in marine organic matter and isotopic fractionation in the global biogeochemical cycle of carbon during the past 800 Ma, Chemical Geology 161 (1999), 103-125.

[33] J. M. Hayes and J. R. Waldbauer, The carbon cycle and associated redox processes through time, Philosophical Transactions of the Royal Society B: Biological Sciences 361 (2006), no. 1470, 931-950.

[34] J. I. Hedges, Global biogeochemical cycles: progress and problems, Marine Chemistry 39 (1992), 67-93.

[35] J. I. Hedges and R. G. Keil, Sedimentary organic matter preservation: an assessment and speculative synthesis, Marine Chemistry 49 (1995), 81-115.

[36] H. D. Holland, The chemistry of the atmosphere and oceans, John Wiley \& Sons, New York, 1978.

[37] W. T. Holser, M. Schidlowski, F. T. Mackenzie, and J. B. Maynard, Biogeochemical cycles of carbon and sulfur, Chemical Cycles in the Evolution of the Earth (C. B. Gregor, R. M. 
Garrels, F. T. Mackenzie, and J. B. Maynard, eds.), John Wiley \& Sons, New York, 1988, pp. 105-173.

[38] Leo P. Kadanoff, Statistical physics, World Scientific Publishing Co., Inc., River Edge, NJ, 2000. Statics, dynamics and renormalization. MR1772071 (2003f:82001)

[39] C. D. Keeling, The Suess effect: ${ }^{13}$ Carbon- ${ }^{14}$ Carbon interrelations, Environment International 2 (1979), no. 4, 229-300.

[40] R. G. Keil and L. M. Mayer, Mineral matrices and organic matter, Treatise on Geochemistry (Second Edition) (H. D. Holland and K. T. Turekian, eds.), vol. 12, Elsevier, Oxford, 2nd ed., 2014, pp. 337-359.

[41] A. H. Knoll, Life on a young planet, Princeton University Press, Princeton, 2003.

[42] A. H. Knoll, R. K. Bambach, D. E. Canfield, and J. P. Grotzinger, Comparative Earth history and late Permian mass extinction, Science 273 (1996), 452-457.

[43] Andrew H. Knoll, Richard K. Bambach, Jonathan L. Payne, Sara Pruss, and Woodward W. Fischer, Paleophysiology and end-Permian mass extinction, Earth and Planetary Science Letters 256 (2007), no. 3-4, 295-313.

[44] C. Korte and H. W. Kozur, Carbon-isotope stratigraphy across the Permian-Triassic boundary: A review, Journal of Asian Earth Sciences 39 (2010), 215-235.

[45] C. Kuehn, A mathematical framework for critical transitions: Bifurcations, fast-slow systems and stochastic dynamics, Physica D: Nonlinear Phenomena 240 (2011), no. 12, 1020-1035.

[46] T. A. Laakso and D. P Schrag, Regulation of atmospheric oxygen during the Proterozoic, Earth and Planetary Science Letters 388 (2014), 81-91.

[47] C. M. Marshall, Explaining the Cambrian "explosion" of animals, Annu. Rev. Earth Planet. Sci. 34 (2006), 355-284.

[48] J. J. Middelburg, A simple rate model for organic matter decomposition in marine sediments, Geochimica et Cosmochimica Acta 53 (1989), 1577-1581.

[49] J. J. Middelburg and F. J. R. Meysman, Burial at sea, Science (Washington) 316 (2007), no. 5829, 1325-1326.

[50] M. Milankovič, Canon of insolation and the ice-age problem, Zavod za udžbenike i nastavna sredstva, 1998.

[51] Elliott W. Montroll and Michael F. Shlesinger, On $1 / f$ noise and other distributions with long tails, Proc. Nat. Acad. Sci. U.S.A. 79 (1982), no. 10, 3380-3383. MR657549 (83h:62034)

[52] R. A. Muller and G. J. Macdonald, Ice ages and astronomical causes, Springer, New York, 2000 .

[53] J. D. Murray, Mathematical biology, 2nd ed., Biomathematics, vol. 19, Springer-Verlag, Berlin, 1993. MR1239892(94j:92002)

[54] L. Och and G. A. Shields, The Neoproterozoic oxygenation event: Environmental perturbations and biogeochemical cycling, Earth-Science Reviews 110 (2012), 26-57.

[55] D. E. Ogden and N. H. Sleep, Explosive eruption of coal and basalt and the end-Permian mass extinction, Proceedings of the National Academy of Sciences 109 (2012), no. 1, 59-62.

[56] J. R. Petit, J. Jouzel, D. Raynaud, N. I. Barkov, J. M. Barnola, I. Basile, M. Bender, J. Chappellaz, M. Davis, G. Delaygue, M. Delmotte, V. M. Kotlyakov, M. Legrand, V. Y. Lipenkov, C. Lorius, L. Pepin, C. Ritz, E. Saltzman, and M. Stievenard, Climate and atmospheric history of the past 420,000 years from the Vostok ice core, Antarctica, Nature 399 (1999), no. $6735,429-436$.

[57] Raymond T. Pierrehumbert, Principles of planetary climate, Cambridge University Press, Cambridge, 2010. MR2778154 (2012d:85008)

[58] A. Plonka, Dispersive kinetics, Kluwer, Boston, 2001.

[59] D. M. Raup and J. J. Sepkoski Jr, Mass extinctions in the marine fossil record, Science 215 (1982), no. 4539, 1501-1503.

[60] M. K. Reichow, M. S. Pringle, A. I. Al'Mukhamedov, M. B. Allen, V. L. Andreichev, M. M. Buslov, C. E. Davies, G. S. Fedoseev, J. G. Fitton, S. Inger, A. Ya. Medvedev, C. Mitchell, V. N. Puchkov, I. Yu. Safonova, R. A. Scott, and A. D. Saunders, The timing and extent of the eruption of the Siberian traps large igneous province: Implications for the end-Permian environmental crisis, Earth and Planetary Science Letters 277 (2009), no. 1-2, 9-20.

[61] J. Ross and M. O. Vlad, Nonlinear kinetics and new approaches to complex reaction mechanisms, Annual Review of Physical Chemistry 50 (1999), 51-78.

[62] D. H. Rothman and D. C. Forney, Physical model for the decay and preservation of marine organic carbon, Science 316 (2007), 1325-1328. 
[63] D. H. Rothman, G. P. Fournier, K. L. French, E. J. Alm, E. A. Boyle, C. Cao, and R. E. Summons, Methanogenic burst in the end-Permian carbon cycle, Proceedings of the National Academy of Sciences 111 (2014), no. 15, 5462-5467.

[64] D. H. Rothman, J. M. Hayes, and R. E. Summons, Dynamics of the Neoproterozoic carbon cycle, Proceedings of the National Academy of Sciences USA 100 (2003), 8124-8129.

[65] M. Schidlowski, Carbon isotopes as biogeochemical recorders of life over 3.8 Ga of Earth history: evolution of a concept, Precambrian Research 106 (2001), 117-134.

[66] D. P. Schrag, J. A. Higgins, F. A. Macdonald, and D. T. Johnston, Authigenic carbonate and the history of the global carbon cycle, Science 339 (2013), no. 6119, 540-543.

[67] S.-Z. Shen, J. L. Crowley, Y. Wang, S. A. Bowringo, D. H. Erwin, P. M. Sadler, C.-Q Cao, D. H. Rothman, C. M. Henderson, J. Ramezani, H. Zhang, Y. Shen, X.-D. Wang, W. Wang, Lin Mu, W.-Z. Li, Y.-G. Tang, X.-L. Liu, L.-J Liu, Y. Zeng, Y.-F Jiang, and Y.-G. Jin, Calibrating the end-Permian mass extinction, Science 334 (2011), 1367-1372.

[68] G. Shields and J. Veizer, Precambrian marine carbonate isotope database: Version 1.1, Geochemistry Geophysics Geosystems 3 (2002), Art. No. 1031.

[69] W. Shockley, On the statistics of individual variations of productivity in research laboratories, Proceedings of the IRE 45 (1957), no. 3, 279-290.

[70] D. M. Sigman and E. A. Boyle, Glacial/interglacial variations in atmospheric carbon dioxide, Nature 407 (2000), no. 6806, 859-869.

[71] T. F. Stocker, D. Qin, G. K. Plattner, M. Tignor, S. K. Allen, J. Boschung, A. Nauels, Y. Xia, V. Bex, and P. M. Midgley, Climate Change 2013: The Physical Science Basis. Contribution of Working Group I to the Fifth Assessment Report of the Intergovernmental Panel on Climate Change, Cambridge University Press, New York, New York, 2013.

[72] H. E. Suess, Radiocarbon concentration in modern wood, Science 122 (1955), no. 3166, 415417.

[73] H. Svensen, S. Planke, A. G. Polozov, N. Schmidbauer, F. Corfu, Y. Y. Podladchikov, and B. Jamtveit, Siberian gas venting and the end-Permian environmental crisis, Earth and Planetary Science Letters 277 (2009), 490-500.

[74] P. Tans and R. Keeling, May 2014, NOAA/ESRL (www.esrl.noaa.gov/gmd/ccgg/trends/) and Scripps Institution of Oceanography (scrippsco2.ucsd.edu/).

[75] Y. A. Vetter, J. W. Deming, P. A. Jumars, and B. B. Krieger-Brockett, A predictive model of bacterial foraging by means of freely released extracellular enzymes, Microbial Ecology 36 (1998), 75-92.

[76] M. O. Vlad, D. L. Huber, and J. Ross, Rate statistics and thermodynamic analogies for relaxation processes in systems with static disorder: Application to stretched exponential, J. Chem. Phys. 106 (1997), 4157-4167.

[77] O. H. Walliser (ed.), Global events and event stratigraphy in the Phanerozoic, Springer, Berlin, 1996.

[78] C. Wunsch, The spectral description of climate change including the 100 ky energy, Climate Dynamics 20 (2003), 353-363.

[79] S. A. Zimov, E. A. G. Schuur, and F. S. Chapin III, Permafrost and the global carbon budget, Science 312 (2006), no. 5780, 1612-1613.

Lorenz Center, Department of Earth, Atmospheric, and Planetary Sciences, MasSachusetts Institute of Technology, Cambridge, Massachusetts 02139

E-mail address: dhr@mit.edu 